\title{
Evaluating the microleakage between dentin and composite materials
}

\section{Ocenianie mikroprzecieku pomiędzy zębiną a materiałami złożonymi}

\author{
Alper Özdoğan ${ }^{1, B, D-F}$, Musa Şamil Akyll ${ }^{2, A, C, D}$, Zeynep Yeşil Duymuş̧, ${ }^{3, C, E, F}$ \\ ${ }^{1}$ Department of Prosthodontics, Faculty of Dentistry, Atatürk University, Erzurum, Turkey \\ ${ }^{2}$ Department of Prosthodontics, Faculty of Dentistry, Adnan Menderes University, Aydın, Turkey \\ ${ }^{3}$ Department of Prosthodontics, Faculty of Dentistry, Recep Tayyip Erdoğan University, Rize, Turkey \\ A - research concept and design; $\mathrm{B}$ - collection and/or assembly of data; $\mathrm{C}$ - data analysis and interpretation; \\ $D$ - writing the article; $E$ - critical revision of the article; $F$ - final approval of the article
}

Address for correspondence

Alper Özdoğan

E-mail:alprozdgn@gmail.com

Funding sources

None declared

Conflict of interest

None declared

Acknowledgements

This study was presented as a poster at the $10^{\text {th }}$ International Congress of the Academy of Prosthodontics and Gnathological Society, Antakya, Turkey, April 2012.

Received on January 22, 2018

Reviewed on May 22, 2018

Accepted on May 28, 2018

\begin{abstract}
Background. For successful restoration, it is necessary to minimize the microleakage between dentin and the composite material.

Objectives. The purpose of this study was to evaluate the microleakage of 2 different resin cements (self-adhesive and conventional) on dentin treated with acid, sodium hypochlorite ( $\mathrm{NaOCl}$ ), the acid-NaOCl mixture, the erbium-doped yttrium aluminum garnet (Er:YAG) laser, and their combination.
\end{abstract}

Material and methods. Seventy dentin specimens were divided into 7 groups $(n=10)$ according to the surface treatment. Then, the specimens were divided into 2 subgroups $(n=35)$ according to the resin cement used during cementation with prepared composite resin blocks $5 \mathrm{~mm} \times 11 \mathrm{~mm} \times 3 \mathrm{~mm}$ : self-adhesive resin cement or conventional resin cement. Microleakage was scored and recorded at the occlusal and gingival levels, along the resin-dentin interfaces. The data was analyzed with the use of univariate analysis of variance (two-way ANOVA) and the Kruskal-Wallis test for both resin subgroups.

Results. The obtained results revealed that self-adhesive resin cement and conventional resin cement showed similar microleakage. Etching with sodium hypochlorite, the Er:YAG laser, the acid-NaOCl mixture, and their combination resulted in microleakage comparable to that achieved in acid etching, which is the conventional method of surface treatment.

Conclusions. Microleakage exhibited by self-adhesive resin cement was similar as in the case of conventional resin cement.

Key words: dentistry, resin cement, composites

Słowa kluczowe: stomatologia, cement żywiczny, materiały złożone

DOI

$10.17219 / \mathrm{dmp} / 91780$

Copyright

() 2018 by Wroclaw Medical University

and Polish Dental Society

This is an article distributed under the terms of the

Creative Commons Attribution Non-Commercial License

(http://creativecommons.org/licenses/by-nc-nd/4.0/) 


\section{Introduction}

In dental procedures, microleakage occurs while placing the restorative material in the cavity wall, and results in the passage of bacteria, oral liquids, molecules, ions, and air to the microspace. ${ }^{1} \mathrm{~A}$ number of studies reported that microleakage was a major risk factor for postoperative sensitivity, secondary caries, pulpal necrosis, and pulpal inflammation..$^{2-4}$ Research aimed at identifying materials and methods to prevent microleakage is ongoing. ${ }^{5}$ According to one study, laser technology can minimize microleakage in dentistry. ${ }^{6}$ Other studies have reported that the erbium-doped yttrium aluminum garnet (Er:YAG) laser holds promise and that it could be safely used to remove hard dental tissue. ${ }^{7,8}$

Sodium hypochlorite $(\mathrm{NaOCl})$ has long been used as a deproteinizing agent on dentin. ${ }^{9}$ When $\mathrm{NaOCl}$ is used, collagen fibrils in dentin are dissolved and exposed. Accordingly, the intermediate surface stability increases. ${ }^{10}$ Nassif et al. reported that applying equal volumes of the acid- $\mathrm{NaOCl}$ mixture was more effective than the conventional etching method. ${ }^{11}$

Self-adhesive cements are a new category of resin bonding cements; these cements feature new monomers, fillings and initiator technology. ${ }^{12}$ A previous study reported that the use of traditional cements in etching, primer or bonding applications did not require for these cements to bond to dental tissues. ${ }^{13}$

The aim of this study was to investigate the levels of microleakage at the dentin-adhesive interface surface following various treatments (acids, $\mathrm{NaOCl}$, the acid- $\mathrm{NaOCl}$ mixture, the Er:YAG laser, and the combinations of these modalities) and cementation with self-adhesive and conventional resin cements.

\section{Material and methods}

The study sample consisted of 70 caries-free molar teeth. The teeth were collected after informed consent had been obtained according to the protocols approved by the review board of the Faculty of Dentistry of Atatürk University, Erzurum, Turkey. The teeth were stored in distilled water at $4^{\circ} \mathrm{C}$ until use. The teeth were cut by a diamond saw in the occluso-gingival direction, $3 \mathrm{~mm}$ below the occlusal surface and at the distance of $1 \mathrm{~mm}$ from the cementoenamel junction under water cooling. The samples were then embedded in autopolymerized acrylic resin blocks using a teflon mold, in which the buccal surfaces were cut out. The buccal surfaces of the teeth were then cut by a diamond bur under water until the dentin of the teeth was reached (Fig. 1). The samples were divided into the following 7 groups ( $\mathrm{n}=10$ in each group) according to the surface treatment applied:

- group 1: phosphoric acid (37\%) was applied for $15 \mathrm{~s}$, followed by washing with water; to avoid overdrying the surface, excess water was removed using absorbent paper;

- group 2: $\mathrm{NaOCl}$ (5.25\%) was applied for $2 \mathrm{~min}$, and the surface was then washed with water for $30 \mathrm{~s}$; to avoid overdrying the surface, excess water was removed using absorbent paper;

- group 3: equal volumes of the acid and $\mathrm{NaOCl}(50 \%$ phosphoric acid and $50 \% \mathrm{NaOCl}$ ) was applied for $15 \mathrm{~s}$, followed by washing with water; to avoid overdrying the surface, excess water was removed using absorbent paper;

- group 4: the Er:YAG laser $\left(D_{E K A}{ }^{\circledR}\right.$ Smart, Calenzano, Italy) at a wavelength of $2940 \mathrm{~nm}$ (output power $-3.2 \mathrm{~W}$, length $-100 \mathrm{~mJ}$, distance $-2 \mathrm{~mm}$ ) was applied to the dentin surface for $40 \mathrm{~s}$ under water;

- group 5: the dentin surface was treated with the Er:YAG laser (as in group 4) and additionally, the surface was treated with phosphoric acid (37\%) (as in group 1);

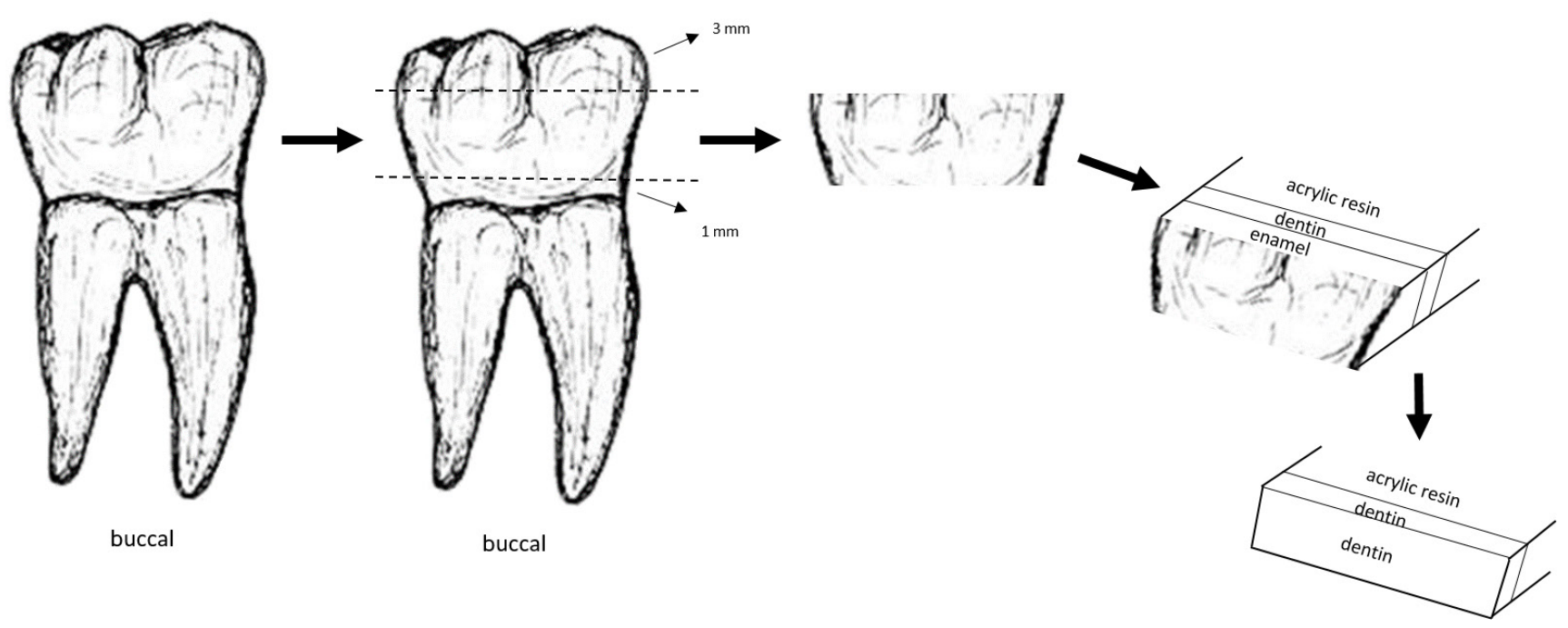

Fig. 1. The schematized tooth preparation 
- group 6: the dentin surface was treated with the Er:YAG laser (as in group 4) and additionally, the surface was treated with $\mathrm{NaOCl}$ (as in group 2);

- group 7: the dentin surface was treated with the Er:YAG laser (as in group 4) and the acid- $\mathrm{NaOCl}$ mixture (as in group 3).

Cementation with resin cement was applied to the sample surfaces using composite blocks, with dimensions of $5 \mathrm{~mm} \times 11 \mathrm{~mm} \times 3 \mathrm{~mm}$ (thickness). The composite blocks were produced using a Plexiglas mold. The mold contained blanks of the same dimensions as the blocks. The composite resin (Quadrant Universal ${ }^{\circledR}$ LC; Cavex $\mathrm{GmbH}$, Ofterdingen, Germany) was placed in 2 stages, $1.5 \mathrm{~mm}$ each time, in accordance with the manufacturer's instructions. At each stage, the surface was polymerized for $40 \mathrm{~s}$ using LED light. The cementation surfaces of the obtained blocks were polished using composite rubbers (Sof-Lex $^{\mathrm{TM}}$; 3M, Maplewood, USA).

After the aforementioned surface treatments, the samples in each group were divided into 2 groups, depending on the type of resin cement (conventional dual-cure resin cement or self-adhesive dual-cure resin cement) used for cementation. In the conventional resin cement (CRC) group, the composite blocks were cemented to half of the samples ( $\mathrm{n}=35$ ) using conventional dual-cure resin cement (Clearfil Esthetic ${ }^{\circledR}$ Cement; Kuraray Co., Ltd., Kurashiki, Japan). During cementation, additional acid etching was not applied to the dentin surface. All other cementation steps were applied according to the manufacturer's recommendations. In the self-adhesive resin cement (SARC) group, the composite blocks were cemented to half of the samples $(n=35)$ using self-adhesive dualcure resin cement (Rely X U200; 3M). After the cementation of the composite blocks to the dentin surfaces, finger pressure was applied. To ensure standardization, the same researcher performed all the cementations. Residue cement was cleaned using a brush. The resin cement was polymerized from different directions using LED light for a total of $40 \mathrm{~s}$.

\section{Evaluation of microleakage}

Two consecutive layers of nail varnish were applied to the entire surfaces of the dentin, approx. $1 \mathrm{~mm}$ from the bonding area of the composite-dentin interface. The samples were then immersed in $0.5 \%$ basic fuchsin solution (Basic Violet 14; Changzhou Xincheng Weiye Chemical Co., Ltd., Changzhou, China) for $24 \mathrm{~h}$ at room temperature. Next, the samples were pulled out from the solution, washed with water and dried. Then, they were sectioned into slices using a diamond saw in the bucco-lingual direction under water. Each cut surface was examined under a stereomicroscope (Novex RZ; Euromex, Amsterdam, the Netherlands) at $\times 40$ magnification. Microleakage at the dentin-adhesive interface surface was examined only at the occlu- sal and gingival levels. The level of microleakage was scored as follows ${ }^{14}$ :

- 0 point: no paint penetration (Fig. 2);

-1 point: limited penetration $(1 \mathrm{~mm})$;

-2 points: penetration into the dentin-adhesive interface surface at the depth of $2 \mathrm{~mm}$;

-3 points: penetration into the dentin-adhesive interface surface at the depth of $3 \mathrm{~mm}$.

\section{Statistical analysis}

The statistical analyses of the obtained data were performed using a two-way analysis of variance (ANOVA) and the Kruskal-Wallis test. A p-value $<0.05$ was considered significant.

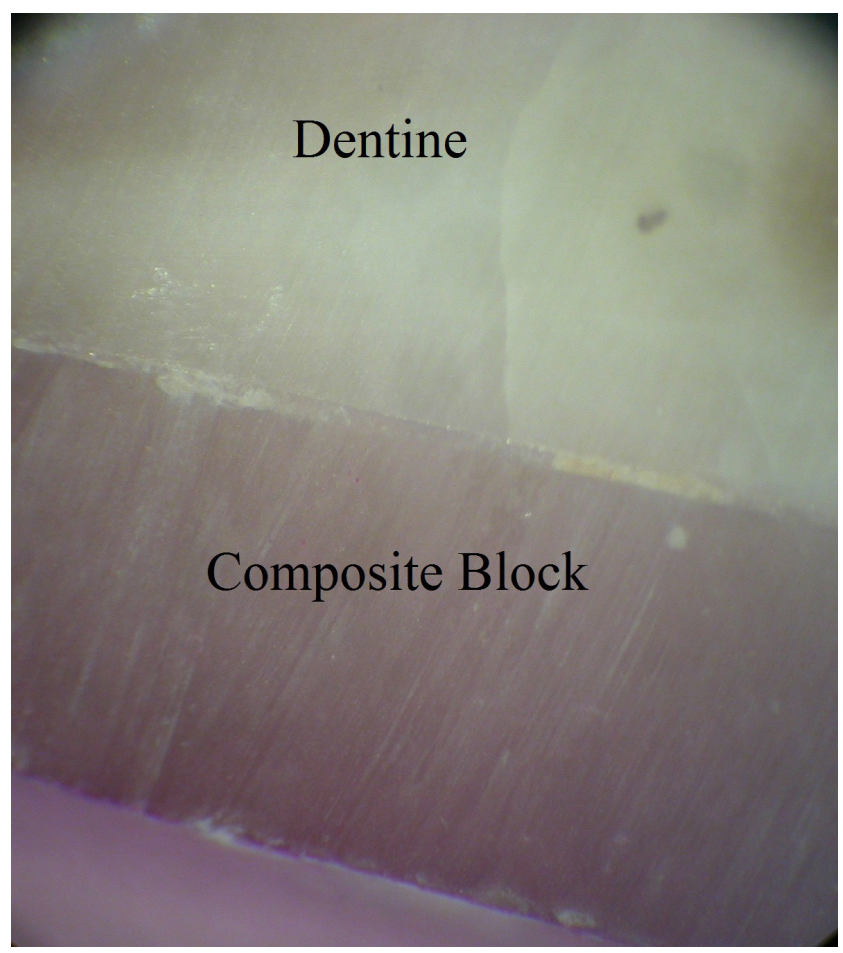

Fig. 2. No dye penetration of the bonding surface

\section{Results}

The mean microleakage results are shown in Table 1 and the dye penetration data is presented in Fig 3. The results of the two-way ANOVA and Kruskal-Wallis test revealed no statistically significant differences between the resin cement and surface treatment groups $(\mathrm{p}>0.05)$. The highest microleakage mean score $(0.80)$ at the dentin-adhesive interface surface was obtained in the group treated with CRC and the Er:YAG laser. The lowest mean microleakage score (0.28) at the dentin-adhesive interface surface was obtained in the group treated with the acid- $\mathrm{NaOCl}$ mixture and SARC. The results of the microscopic examination revealed no marked difference in dye penetration between the groups. These findings suggested that there was no statistically significant difference between the groups. 
Table 1. The mean score of microleakage

\begin{tabular}{|c|c|c|c|}
\hline \multirow{2}{*}{ Surface treatment } & \multirow{2}{*}{$\begin{array}{l}\text { Resin } \\
\text { cement }\end{array}$} & \multicolumn{2}{|c|}{ Microleakage score } \\
\hline & & mean & $\pm \mathrm{SD}$ \\
\hline \multirow{2}{*}{ Group 1 (acid) } & CRC & 0.50 & \pm 0.53 \\
\hline & SARC & 0.62 & \pm 0.52 \\
\hline \multirow{2}{*}{ Group 2 (NaOCl) } & CRC & 0.62 & \pm 0.52 \\
\hline & SARC & 0.75 & \pm 0.46 \\
\hline \multirow{2}{*}{ Group 3 (acid-NaOCl) } & CRC & 0.62 & \pm 0.92 \\
\hline & SARC & 0.28 & \pm 0.49 \\
\hline \multirow{2}{*}{ Group 4 (Er:YAG) } & CRC & 0.80 & \pm 0.42 \\
\hline & SARC & 0.62 & \pm 0.52 \\
\hline \multirow{2}{*}{ Group 5 (Er:YAG+acid) } & CRC & 0.62 & \pm 0.92 \\
\hline & SARC & 0.75 & \pm 0.89 \\
\hline \multirow{2}{*}{ Group 6 (Er:YAG+NaOCl) } & CRC & 0.29 & \pm 0.46 \\
\hline & SARC & 0.62 & \pm 0.74 \\
\hline \multirow{2}{*}{ Group 7 (Er:YAG+acid-NaOCl) } & CRC & 0.75 & \pm 0.71 \\
\hline & SARC & 0.75 & \pm 0.71 \\
\hline
\end{tabular}

Er:YAG - erbium-doped yttrium aluminum garnet lase; CRC - conventional resin cement; SARC - self-adhesive resin cement; SD - standard deviation.

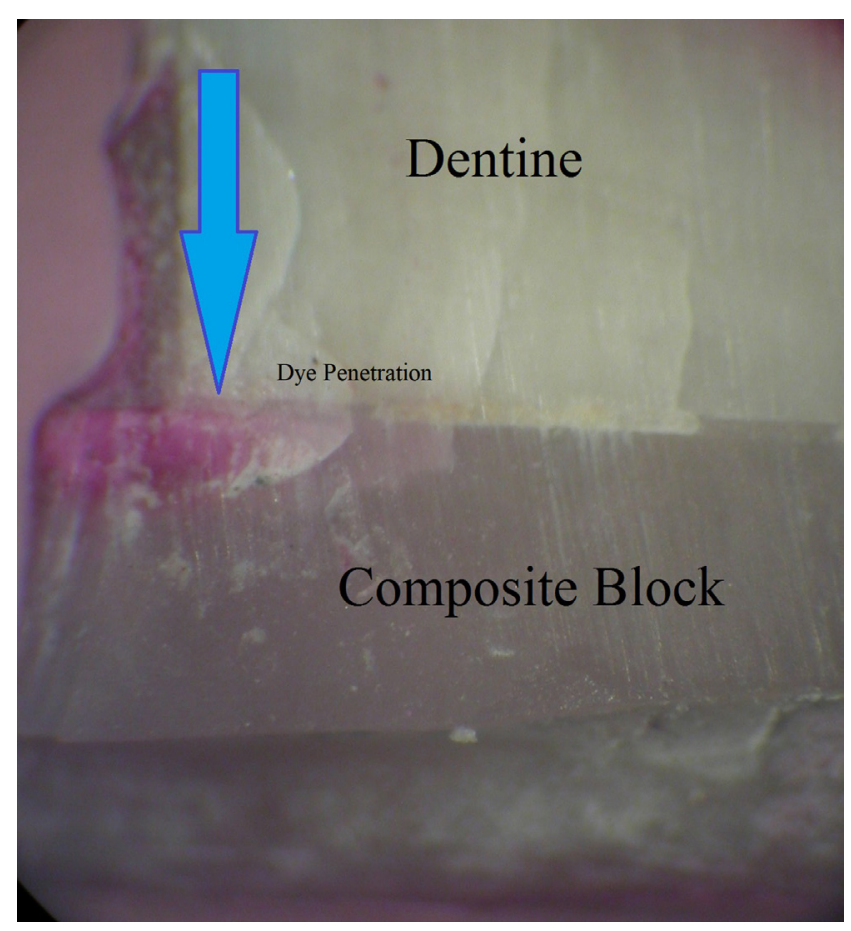

Fig. 3. Dye penetration of the bonding surface

\section{Discussion}

The results of the present study indicated that microleakage following etching with $\mathrm{NaOCl}$, the Er:YAG laser, the acid- $\mathrm{NaOCl}$ mixture, and the combinations of these modalities was similar to that obtained using conventional acid etching surface treatment methods.

In the case when collagen fibrils are not exposed, $\mathrm{NaOCl}$ is commonly applied after acid etching to protect the dentin bonding interface. ${ }^{9,11,15}$ In the present study, the effect of $\mathrm{NaOCl}$ was examined independently of acid etching, and microleakage scores were determined after both CRC and SARC acid etching. The acid-NAOCl mixture seems to modify the exposed collagen by removing the 'collagen smear layer', and this leads to the formation of a stable connection interface, thereby reducing microleakage. ${ }^{11}$ The acidic nature of SARC may have contributed to increased stability of bonding. It can be explained by the minimal average microleakage obtained in this research in the case of the SARC samples treated with the acid- $\mathrm{NaOCl}$ mixture.

Previous studies reported discordant effects of laser applications on microleakage. Although Obeidi et al. reported that application of the neodymium-doped yttrium aluminum garnet (Nd:YAG) laser reduced the amount of microleakage, Navarro et al. and Aranha et al. both reported that laser application did not affect microleakage. ${ }^{16-18}$ According to previous research, an output power of more than $2 \mathrm{~W}$ was appropriate for the dentin surface. ${ }^{19}$ The Er:YAG laser used in the present study had an output power of 3.2 W, and the level of microleakage was similar to that obtained using conventional acid. Thus, based on the findings of the present study, the laser application did not influence the level of microleakage.

The results obtained in this study suggest that the acid- $\mathrm{NaOCl}$ mixture appears to be sufficient to reduce microleakage. Additional surface treatments had no effect on reducing leakage at the dentin-composite interface. Although the findings were not statistically significant, further modification studies of the acid- $\mathrm{NaOCl}$ combination may be considered. Future research could also evaluate the effect of different restorative materials treated with acids and agents of different chemical content on microleakage between dentin and restorative materials.

\section{Conclusions}

Within the limitations of this study, microleakage at the dentin-resin cement interface can be reduced using the acid-NaOCl mixture and SARC. The level of microleakage observed using SARC was similar to that obtained using CRC. The levels of microleakage observed following the application of $\mathrm{NaOCl}$, the Er:YAG laser, the acid$\mathrm{NaOCl}$ mixture, and the combinations of these modalities were similar.

\section{References}

1. Perdigao J, Swift EJ. Fundamental concept of enamel and dentin adhesion. In: Roberson T, Heymann HO, Swift EJ Jr., eds. Sturdevant's Art and Science of Operative Dentistry. St. Louis, MO: Mosby, Inc.; 2006:130.

2. Murray PE, Hafez AA, Smith AJ, Cox CF. Bacterial microleakage and pulp inflammation associated with various restorative materials. Dent Mater. 2002;18(6):470-478.

3. Türkün M, Türkün LS, Kalender A. Effect of cavity disinfectants on the sealing ability of nonrinsing dentin-bonding resins. Quintessence Int. 2004;35(6):469-476. 
4. Brännström M. The cause of postrestorative sensitivity and its prevention. J Endod. 1986;12(10):475-481.

5. Akin H, Tugut F, Akin GE, Guney U, Mutaf B. Effect of Er:YAG laser application on the shear bond strength and microleakage between resin cements and Y-TZP ceramics. Lasers Med Sci. 2012;27(2):333-338.

6. Siso HS, Kustarci A, Göktolga EG. Microleakage in resin composite restorations after antimicrobial pre-treatments: Effect of KTP laser, chlorhexidine gluconate and Clearfil Protect Bond. Oper Dent. 2009;34(3):321-327.

7. Hibst R, Keller U. Experimental studies of the application of the Er:YAG laser on dental hard substances: I. Measurement of the ablation rate. Lasers Surg Med. 1989;9(4):338-344.

8. Brulat N, Leforestier E, Rocca JP, Darquet-Cerretti E, Bertrand MF Shear bond strength of self-etching adhesive systems to Er:YAG laser-prepared dentine with and without pulpal pressure simulation. Photomed Laser Surg. 2008;26(6):579-583.

9. Sano H, Yoshikawa T, Pereira PN, et al. Long-term durability of dentin bonds made with a self-etching primer, in vivo. J Dent Res. 1999;78(4):906-911.

10. Baseggio W, Consolmagno EC, de Carvalho FL, et al. Effect of deproteinization and tubular occlusion on microtensile bond strength and marginal microleakage of resin composite restorations. J Appl Oral Sci. 2009;17(5):462-466.

11. Nassif MS, El-Korashy DI. Phosphoric acid/sodium hypochlorite mixture as dentin conditioner: A new approach. J Adhes Dent. 2009;11(6):455-460.

12. Radovic I, Monticelli F, Goracci C, Vulicevic ZR, Ferrari M. Self-adhesive resin cements: A literature review. J Adhes Dent. 2008;10(4):251-258.

13. Gerth HU, Dammaschke T, Züchner H, Schäfer E. Chemical analy sis and bonding reaction of RelyX Unicem and Bifix composites a comparative study. Dent Mater. 2006;22(10):934-941.

14. Arhun N, Arman A, Cehreli SB, Arikan S, Karabulut E, Gülşahi K. Microleakage beneath ceramic and metal brackets bonded with a conventional and an antibacterial adhesive system. Angle Orthod. 2006;76(6):1028-1034.

15. Inoue S, Murata $\mathrm{Y}$, Sano $\mathrm{H}$, Kashiwada T. Effect of $\mathrm{NaOCl}$ treatment on bond strength between indirect resin core-buildup and dentin. Dent Mater J. 2002;21(4):343-354.

16. Obeidi A, Ghasemi A, Azima A, Ansari G. Effects of pulsed Nd:YAG laser on microleakage of composite restorations in class $\mathrm{V}$ cavities. Photomed Laser Surg. 2005;23(1):56-59.

17. Navarro RS, Gouw-Soares S, Cassoni A, Haypek P, Zezell DM, de Paula Eduardo $C$. The influence of erbium:yttrium-aluminum-garnet laser ablation with variable pulse width on morphology and microleakage of composite restorations. Lasers Med Sci. 2010;25(6):881-889.

18. Aranha AC, Turbino ML, Powell GL, Eduardo Cde P. Assessing microleakage of class $\mathrm{V}$ resin composite restorations after Er:YAG laser and bur preparation. Lasers Surg Med. 2005;37(2):172-177.

19. Capa N, Aykor A, Ozel E, Calikkocaoglu S, Soyman M. Effect of Er:YAG laser irradiations on shear bond strength of three self-adhesive resin cements to dentin. Photomed Laser Surg. 2010;28(6):809-821. 
